\title{
EL DERECHO A RECIBIR INFORMACIÓN VERAZ EN EL SISTEMA CONSTITUCIONAL. EL EJERCICIO PROFESIONAL DEL PERIODISMO COMO GARANTÍA DEMOCRÁTICA*
}

\author{
The right to receive faithful information in the constitutional \\ system. The professional exercise of journalism \\ as a democratic guarantee
}

\author{
Jesús López de Lerma Galán \\ Universidad Rey Juan Carlos (España) \\ jesus.lopezdelerma@urjc.es
}

http://dx.doi.org/10.18543/ed-66(2)-2018pp435-459

Recibido: 30.10 .2018

Aceptado: 21.11.2018

\section{Resumen}

El reconocimiento del derecho a la información en la Constitución de 1978 ha sido determinante para la formación de una opinión pública libre y plural, así como la consolidación del Estado social y democrático de Derecho. Este artículo estudia el principio de veracidad como garantía jurídica, analizando la jurisprudencia del Tribunal Constitucional y diferentes posicionamientos doctrinales en relación a esta materia. Una investigación centrada en el ejercicio activo del derecho a la información, que también analizará la figura del periodista y su obligación de actuar de forma diligente, al objeto de obtener la protección constitucional.

* Cómo citar / Citation 'Chicago-Deusto' (Autor-fecha / Author-date / Lista de referencias / Reference list entries): López de Lerma Galán, Jesús. 2018. «El derecho a recibir información veraz en el sistema constitucional. el ejercicio profesional del periodismo como garantía democrática». Estudios de Deusto 66, n. ${ }^{\circ}$ 2: 435-459. http://dx.doi. org/10.18543/ed-66(2)-2018pp435-459. 


\title{
Palabras clave
}

Constitución; Veracidad; Libertad; Honor; Intimidad; Opinión pública.

\begin{abstract}
The recognition of the right to information in the 1978 Constitution has been decisive for the formation of a free and plural public opinion, as well as the consolidation of the social and democratic State of Law. This article studies the principle of veracity as a legal guarantee, analyzing the jurisprudence of the Constitutional Court and different doctrinal positions in relation to this matter. An investigation focused on the active exercise of the right to information, which will also analyze the journalist's role and his obligation to act diligently, in order to obtain constitutional protection.
\end{abstract}

\section{Keywords}

Constitution; Veracity; Freedom; Honor; Intimacy; Public opinion. 


\begin{abstract}
SUMARIO: I. INFORMACIÓN VERAZ COMO GARANTÍA JURIDICA EN LAS SOCIEDADES DEMOCRÁTICAS. 1. El concepto de veracidad. Significado y naturaleza jurídica. 2. Veracidad frente a verdad. II. EL PRINCIPIO DE VERACIDAD. RECONOCIMIENTO CONSTITUCIONAL DEL DERECHO A LA INFORMACIÓN. 1. La veracidad como objeto de la información. 2. La distinción de la realidad fáctica. Información, opinión y juicios de valor. 3. La formulación de la información veraz en el periodismo. Elementos y características. III. EL VALOR JURÍDICO DE LA VERACIDAD, LA COLISIÓN DE DERECHOS Y EL EJERCICIO DEL DERECHO A LA INFORMACIÓN. 1. La veracidad como límite del derecho a la información. 2. Diligencia profesional y responsabilidad del autor. 3. La protección constitucional en el ejercicio del derecho a la información. BIBLIOGRAFÍA.
\end{abstract}

\title{
I. LA INFORMACIÓN VERAZ COMO GARANTÍA JURÍDICA EN LAS SOCIEDADES DEMOCRÁTICAS
}

\section{El concepto de veracidad. Significado y naturaleza jurídica}

El derecho a la información a la vez que constituye un derecho subjetivo de libertad cumple una función de garantías en las sociedades democráticas. Así, podemos defender que las Constituciones de los Estados democráticos tienden a concebir el derecho a la información o la libertad de expresión como auténticos derechos humanos, reconociéndolos y protegiéndolos con sistemas específicos de garantías ${ }^{1}$. La veracidad ha sido uno de los elementos que mayor complejidad ha generado en el estudio del derecho a la información desde la disciplina jurídica y periodística. La propia redacción que hace el art. 20. 1 d) de la Constitución española puede incrementar la confusión, al aludir a la expresión «información veraz», una noción cercana a la verdad ${ }^{2}$, que exige un desarrollo posterior para dotarlo de sentido.

El derecho a recibir información veraz se ha convertido en uno de los principales fundamentos de la realidad democrática, que nos ha permitido consolidar una opinión pública plural y libremente formada, contribuyendo a la consolidación del Estado social y democrático de derecho. La veracidad, se convierte así en el elemento garante de la constitucionalidad de un derecho tan básico como es el de informar. Un término objeto de controversia, cuya

${ }^{1}$ Gutierrez David, M. ${ }^{a}$ Estrella: Justicia y medios de comunicación. Claves para la buena praxis de los derechos informativos, Editorial Fragua, Madrid, 2007, p. 56.

2 Azurmendi Adarraga, Ana: «De la verdad informativa a la «información veraz» de la Constitución española de 1978. Una reflexión sobre la verdad exigible desde el derecho de la información», Comunicación y Sociedad, Vol. XVIII, Núm. 2, 2005, p. 9. 
naturaleza jurídica debemos de definir, puesto que lo que realmente se defiende es propiamente una información verídica, comprobada y contrastada según los cánones de la profesión informativa. Ese deber de contrastar la información por parte del periodista, será lo que nos determine la veracidad de una noticia.

El propio término «veraz», que utiliza la Constitución, puede generar cierta imprecisión, como venimos defendiendo. En este sentido se debe matizar que la verdad o falsedad debe predicarse de la información mientras que la veracidad o su ausencia deberá serlo frente a la actuación del informador ${ }^{3}$. Todo ello hace de la veracidad un presupuesto necesario para que el ejercicio de este derecho se beneficie de la tutela constitucional ${ }^{4}$. Además, debemos añadir que los medios de comunicación tienen una clara función social y política, pues no son sino una red de poderes que se controlan y contrapesan mutuamente ${ }^{5}$, haciendo de las noticias su núcleo de actuación.

En un primer momento la jurisprudencia del Tribunal Constitucional consideró que el derecho a comunicar información era una concreción del derecho a la libertad de expresión, y que el derecho a recibir la información era un simple reverso el derecho a transmitirla. Posteriormente, la jurisprudencia estableció matizaciones en su interpretación, destacando lo que se entiende como libertad de expresión en sentido estricto consistente en «aquella que expresa y difunde libremente pensamientos, ideas y opiniones...» (20. 1 a) $\mathrm{CE}$ ), y aquella otra más relacionada con el derecho a la información que establece «el derecho a comunicar o recibir libremente información veraz por cualquier medio de difusión» (20.1 d) CE). Esto nos permite diferenciar entre una libertad de expresión cuyo objeto son los pensamientos, ideas y opiniones, y por otro lado el derecho a la información más relacionado con los hechos y las noticias, que debe ser concreto y objetivo ${ }^{6}$. A todo ello no debemos obviar, tal y como señala Habermas, que en el periodismo podemos encontrar que información y opinión pueden entrelazarse ${ }^{7}$. La distinción entre la libertad de expresión en un sentido más universalista, y el derecho a

3 Torres del Moral, Antonio: Principios de derecho constitucional español, Servicio de Publicaciones de la Facultad de Derecho, Universidad Complutense, Madrid, 2010, p. 446.

${ }^{4}$ Navas Castillo, Florentina: «Libertad de expresión y derecho a la información» en Torres del Moral, Antonio: Libertades informativas, Editorial Colex, Madrid, 2009, p. 103.

${ }_{5}$ Escobar de la Serna, Luis: Principios de derecho de la información., Editorial Dykinson, Madrid 2000, p. 64.

${ }^{6}$ García Guerrero, José Luis: «Una visión de la libertad de comunicación desde la perspectiva de las diferencias entre libertad de expresión, en sentido estricto, y libertad de información», Teoría y realidad constitucional nº. 20, UNED, 2007, pp. 370 - 371.

${ }^{7}$ Habermas, Jürgen: Historia y crítica de la opinión pública. La transformación estructural de la vida pública, Gustavo Gili, Barcelona, 1981, p. 210. 
la información mucho más particular, centrado en la actividad periodística, supone un parámetro de interpretación más adaptado a la realidad práctica que ha exigido a la jurisprudencia constitucional desarrollar una completa doctrina en relación al principio de veracidad, como iremos explicando en esta investigación.

\section{Veracidad frente a verdad}

Hay que señalar que cuando se habla del «derecho a la información» hay autores que entienden que, implícitamente, se está introduciendo la referencia a la verdad ${ }^{8}$, aunque no siempre es así. La doctrina ha destacado que la «verdad única» no existe, ya que el pluralismo implica una diferente visión de análisis de la realidad social. Eso significa que un mismo hecho puede ser explicado de diversas y plurales maneras, en un ejercicio de la libertad informativa, dejando patente que todas esas formas son veraces 9 . Hay que defender que el requisito democrático de la veracidad implica la necesidad de entender que ante un mismo hecho pueden existir diversos criterios de interpretación y explicación, aunque la realidad fáctica sea única. Esa pluralidad de análisis de la realidad es lo que hace que la actividad informativa y plural esté llena de matices, por eso es más correcto incidir en el concepto de veracidad en vez de una única e inalterable verdad.

Si hacemos una retrospección histórica podemos encontrar que la verdad se imponía acallando al que la discute o la niega, porque la verdad, ese bien preciado de la teoría clásica, su búsqueda, descubrimiento y posesión, es la sustancia del Estado, y a su luz alumbra la Justicia. Será la Ilustración la que mina esa profunda fe en la verdad única e indiscutible para todos los órdenes de la vida, afirmando que en política no hay verdad sino opinión ${ }^{10}$. Todo ello nos lleva a entender que la búsqueda de la verdad, como principio universal, nace en la Ilustración, y de esos conceptos utópicos de verdad, se desarrollará posteriormente el concepto de «veracidad».

Hay sectores doctrinales que consideran que la verdad puede ser entendida como una categoría metafísica que no constituye un límite al derecho a la información sino en su fundamento, siendo considerada como la adecuación

${ }^{8}$ Brajnovic, Luka: El ámbito cientifico de la Información, Eunsa, Pamplona, 1979, p. 60 .

9 De Carreras Serra, Lluis: Régimen jurídico de la información. Periodistas y medios de comunicación, Ariel Derecho, Barcelona, 1996, p. 47.

${ }_{10}$ Viillaverde Menéndez, Ignacio: «Introducción histórica a las libertades de información y expresión», en VV. AA: La libertad de información y de expresión. Actas de las VII Jornadas de la Asociación de Letrados del Tribunal Constitucional, Centro de Estudios Políticos y Constitucionales, Madrid, 2002, pp. 13-14. 
aceptable entre el hecho y el mensaje ${ }^{11}$. En épocas más actuales se abrirá todo un debate sobre el concepto de verdad en una información, y sobre todo se verá la diferenciación entre la elaboración de una noticia, donde se busca la verdad de los hechos, y la opinión que podamos tener sobre esa misma noticia, en la que entrarían elementos más valorativos y subjetivos. Es aquí donde encontramos como el derecho evoluciona desde una concepción clásica de «verdad», hacia un posicionamiento más cercano al actual donde utilizamos el término «veracidad», que sin ser una verdad absoluta puede acercarse a la realidad más cercana de los hechos que conforman una noticia.

La verdad es un valor supremo de la información, aunque debemos matizar que tanto la generación de debate y crítica, desde los medios de comunicación, como la difusión de opiniones y hechos cuando atañen a personas o asuntos públicos, son valores que gozan de una mayor protección, según señala Muñoz Machado. Esto nos hace entender la difusión de la información como un acto que no puede prescindir de la verdad al divulgar los hechos. Esa trascendencia constitucional del derecho de información, exige al periodista o personas que hayan divulgado la información, una actitud positiva hacia la verdad, de manera que se pueda probar que ha tratado de encontrarla agotando las fuentes disponibles. Si esta actitud se da, aunque la información no sea totalmente exacta, quedaría protegida por la Constitución ${ }^{12}$. Avanzamos de un presupuesto jurídico esencial para dilucidar posibles conflictos, al analizar la naturaleza de la verdad como justificación de la actuación informativa.

La tesis que ha justificado más prolongadamente la existencia de la libertad de comunicación señala que sólo el debate libre permite el descubrimiento de la verdad ${ }^{13}$. Si un profesional de la información busca la verdad, como prioridad en su actuación, estará respondiendo a los criterios de protección que le otorga la Constitución, pero si lo que busca es alterar esa realidad con informaciones no contrastadas, la protección de la norma constitucional se pierde.

El Tribunal Constitucional ha profundizado en el análisis de los conceptos de veracidad y verdad. El artículo 20.1 d) no protege la narración de hechos verdaderos o judicialmente probados, sino la veracidad, es decir que quien informa ha realizado un comportamiento diligente en la comprobación de los hechos que desea narrar, entendiendo esta circunstancia cuando la

${ }^{11}$ Cremades, Javier: Los limites de la libertad de expresión en el ordenamiento jurídico español, Ley-Actualidad, Madrid, 1995, p. 234.

12 Muñoz Machado, Santiago: Libertad de prensa y procesos por difamación, Editorial Ariel, Barcelona, 1988, pp. 154-155.

13 García Guerrero, José Luis: «Publicidad y libertad de expresión en el ordenamiento constitucional español», Derecho Privado y Constitución, $N^{o} .10$, 1996, p. 129. 
información ha sido suficientemente contrastada ${ }^{14}$. El Tribunal Constitucional así lo expone en la STC 105/1990, de 6 de junio cuando explica que «información veraz es aquella información comprobada según los cánones de la profesionalidad informativa» ${ }^{15}$. La jurisprudencia marca uno de los requisitos fundamentales para dotar de contenido al artículo $20.1 \mathrm{~d}$ ) que es la exigencia de veracidad. No podemos entender un ejercicio profesional del derecho a la información sin este requisito, tal y como lo determina la jurisprudencia al definirlo como un comportamiento diligente en la comprobación de los hechos objeto de la noticia.

\section{EL PRINCIPIO DE VERACIDAD. RECONOCIMIENTO CONSTITUCIONAL DEL DERECHO A LA INFORMACIÓN}

\section{La veracidad como objeto de la información}

El objeto que la Constitución española protege con el derecho a la información es la información veraz, que no siempre podemos identificar con información exacta. Esto exige la necesidad de probar que el periodista, el medio de comunicación actuó de una forma responsable, tal y como el Tribunal Constitucional ha ido consolidando con los años, estableciendo una regla de veracidad que no exige que los hechos o expresiones contenidos en la información sean rigurosamente verdaderos ${ }^{16}$. Este posicionamiento nos lleva a realizar un análisis sobre la doctrina constitucional en relación al principio de veracidad.

La libertad de información tendría por objeto la veracidad, es decir mensajes cuyo contenido único o fundamental son descripciones valorativas de los hechos, tal y como lo explica la STC 105/1983, de 23 de noviembre. Sin embargo, cuando hablamos de libertad de opinión, entendemos el derecho a expresar juicios de valor. En estos casos el juicio valorativo no puede someterse a las pruebas de la veracidad, puesto que no puede contrastarse con supuesto fáctico alguno. Esta doctrina ha sido formulada en contextos muy diferentes por el Tribunal Europeo de Derechos Humanos, en sentencias como la STEDH caso Lingens de 8 de julio de 1986. Aunque debería ser objeto de un análisis más pormenorizado que trasciende al objeto de esta investigación, si al menos citar que el TEDH ha reconocido en su jurisprudencia que la

${ }^{14}$ Fernández Montalvo, Rafael: «Las libertades de información y expresión en el ámbito administrativo» en VV. AA: La libertad de información y expresión. Actas de las VII Jornadas de la Asociación de Letrados del Tribunal Constitucional, Centro de Estudios Políticos y Constitucionales, Madrid, 2002, p. 127.

15 STC 105/1990 de 6 de junio, FJ 5 ${ }^{\circ}$.

16 Azurmendi Adarraga, Ana: Derecho a la información: guía jurídica para profesionales de la comunicación, Ceunsa, Navarra 2001, p. 81. 
libertad de expresión en sentido amplio constituye uno de los pilares fundamentales de la sociedad democrática y una de las condiciones para que ésta progrese ${ }^{17}$. Este posicionamiento ha ayudado a los Estados democráticos a matizar su propia jurisprudencia constitucional, determinando los límites entre la libertad expresión e información, así como las diferencias en relación a la opinión y el hecho noticioso.

Respecto a la evolución que se ha producido en el desarrollo del principio de veracidad, debemos señalar que no será hasta finales de los años ochenta el momento en el que el Tribunal Constitucional, desarrolle el contenido de la expresión de «información veraz». Anteriormente había mantenido una línea de interpretación coherente con los planteamientos de la verdad informativa característicos del ámbito periodístico ${ }^{18}$. La Sentencia 6/1988, de 21 de enero, supuso un cambio en el concepto establecido pues supone entender que la «veracidad» no equivale a verdad, sino que se trata de un deber de diligencia del informador que contrasta los datos ${ }^{19}$, es decir una actuación profesional que enfrenta varias fuentes para reconstruir la realidad.

Hay que explicar que la doctrina jurisprudencial sobre la veracidad ha sido elaborada principalmente para los profesionales de la información, pero es aplicable a los demás titulares que la ejercen. Además, después de la sentencia citada, la veracidad se convierte en una exigencia intrínseca de la protección constitucional de la información, dejando de ser una garantía del pluralismo informativo ${ }^{20}$, para tener un mayor significado jurídico.

La información rectamente obtenida y difundida queda protegida constitucionalmente, y aunque son inevitables las informaciones erróneas en el debate libre, hemos de tener en cuenta como destaca Torres del Moral, que «si se impusiera la verdad como condición del derecho a informar, la única garantía de seguridad jurídica sería el silencio» ${ }^{21}$. Así lo ha mantenido el Tribunal Constitucional en diversas sentencias como la referida STC 6/1988 ${ }^{22}$, que defiende la información rectamente obtenida, dejando claro que el

17 Véase entre otras STEDH de 8 de julio de 1986 «caso Lingens»; STEDH de 2 de marzo de 1987, «caso Mathieu-Mohín y Clerfayt»; STEDH de 19 de febrero de 1998 «caso Browman» y STEDH de 27 de febrero de 2001, «caso Jerusalem»;

18 Azurmendi Adarraga, Ana: «De la verdad informativa a la «información veraz» de la Constitución...», op. cit., p. 28.

19 STC 6/1988, de 21 de enero, FJ $5^{\circ}$.

${ }^{20}$ García Guerrero, José Luis: «La libertad de comunicación» en García Guerrero, José Luís: Los derechos fundamentales. La vida, la igualdad y los derechos de libertad, Tirant Lo Blanch, Madrid, 2013, p. 171.

${ }^{21}$ Torres del Moral, Antonio: «Límites de la libertad de comunicación pública y censura», en Torres del Moral, Antonio: Libertades informativas, Editorial Colex, Madrid, 2009 , p. 164.

22 STC 6/1988, de 21 de enero, FJ $5^{\circ}$. 
ordenamiento no ampara a quien actúa negligentemente o comunica rumores, invenciones o insinuaciones, o la STC 171/1990, de 5 de noviembre, que impone el deber de diligencia en la comprobación razonable de la veraci$\mathrm{dad}^{23}$. En un sentido similar, la sentencia del Tribunal Constitucional 183/1995 establece que la exigencia constitucional de la veracidad de la información, a la que se refiere el artículo 20.1 d) de la Constitución, significa que el informador tiene un especial deber de contrastar las fuentes de la información ${ }^{24}$, en orden a comprobar la veracidad de los hechos.

\section{La distinción de la realidad fáctica. Información, opinión y juicios de valor}

La veracidad no implica una conformación exacta con la realidad fáctica, sino más bien una aproximación que implica un comportamiento adecuado y diligente del profesional de la información. Como ha destacado la jurisprudencia, la Constitución va a proteger también la información errónea, o aquella que no ha sido probada en juicio. Esto implica un deber de diligencia del informador, que le lleva a contrastar esa información, llegando incluso a dejar sin protección constitucional a aquel que menosprecie la verdad. La difusión de informaciones falsas, así como la transmisión de rumores o invenciones insidiosas haría decaer en la información su protección constitucional, pues en cierta manera esta viciando el derecho a la información ${ }^{25}$. Así lo han mantenido en sentencias como STC 172/1990, de 12 de noviembre ${ }^{26}$, en el que ese deber de diligencia y comprobación razonable de la veracidad no queda satisfecho solo con remitirnos a las fuentes, sino que lo convierte en un deber propio del informador.

Lógicamente al entender así ese requisito nos aboca a la necesaria distinción entre hechos y lo que son pensamientos, ideas, opiniones o juicios de valor, puesto que en esa delimitación teórica reside el contenido de los derechos de libertad de expresión e información. Sentencias como STC 223/1992, de 30 de marzo, incidirán en esa distinción tan determinante para resolver las controversias entre derechos ${ }^{27}$. El Tribunal Constitucional admite el error en la información, que puede ser excusable si la información ha sido contrastada o rectamente obtenida, frente a quien obtiene la información con un claro menosprecio de la verdad.

${ }^{23}$ STC $171 / 1990$, de 12 de noviembre, FJ $8^{\circ}$.

${ }^{24}$ STC 183/1995 de 11 de septiembre, FJ $3^{\circ}$.

25 Torres del Moral, Antonio: Principios de derecho constitucional..., op. cit., p. 446.

26 Véase STC 172/1990, de 12 noviembre FJ $3^{\circ}$.

27 La STC 223/1992, de 30 de marzo, en su FJ $2^{\circ}$ establece la diferencia entre hechos y opiniones. Una cuestión sobre la que profundiza el Tribunal Constitucional en las SSTC $107 / 1988,6 / 1988$ y $105 / 1990$. 
El Tribunal Constitucional ha destacado que la libertad de expresión se refiere a juicios y opiniones, mientras que el derecho a la información es la manifestación de los hechos y solo protege la información veraz. Esto implica que la información errónea no está exenta de protección y que las emisiones de apelativos injuriosos son innecesarias para el ejercicio de la labor informativa y no son reconocidos constitucionalmente, tal y como explica la STC 105/1990, de 6 de junio ${ }^{28}$, o la STC 158/2003, de 15 de septiembre $^{29}$, entre otras. Si el informador quiere situarse bajo la esfera de la protección del artículo 20.1 d), debe comprobar la veracidad de los hechos que expone, aunque esa información pueda ser errónea. Lo que no sería admisible sería una injuria o descalificación en el contenido informativo, pues en ese caso se perdería la protección de la norma constitucional.

Insistir que la separación entre hechos y opiniones es importante para resolver los posibles conflictos tal y como destaca la STC 79/2014, de 28 de mayo, pues mientras los hechos son susceptibles de prueba, las opiniones o juicios de valor, por su misma naturaleza, no se prestan a una demostración de exactitud. Esto implica que al que ejercita la libertad de expresión no le sea exigible la prueba de la verdad o diligencia en su averiguación, que condiciona, en cambio, la legitimidad del derecho de información por expreso mandato constitucional ${ }^{30}$. Además, como justifica Cremades mientras que los hechos son susceptibles de prueba por su materialidad, los pensamientos, ideas, opiniones o juicios de valor no se prestan por su naturaleza abstracta a una demostración de su exactitud ${ }^{31}$, lo que hace que entendamos que el límite interno de la veracidad no es por tanto aplicable a la libertad de expresión y si a la libertad de información.

A todo ello, debemos añadir que la consolidación de una información veraz también contribuye a la definición de la opinión pública. En este sentido, tal y como señala Magdaleno, es de vital importancia determinar un marco adecuado en el que se desarrollen determinadas libertades para el funcionamiento del Estado social y democrático de Derecho. Esto significa que la efectiva realización del instituto de la opinión pública necesita mantener la actual preponderancia de la libertad de expresión e información ${ }^{32}$, aunque eso tampoco signifique dotarles de un carácter absoluto dada las

${ }^{28}$ STC 105/1990, de 6 de junio, FJ $5^{\circ}$.

29 STC 158/2003, de 15 de septiembre, FJ $4^{\circ}$.

30 STC 79/2014, de 28 de mayo, FJ $4^{\circ}$. Asimismo podemos citar también SSTC 278/2005, de 7 de noviembre, FJ 2; 174/2006, de 5 de junio, FJ 3; 29/2009, de 26 de enero, FJ 2, y 50/2010, FJ 4.

31 Cremades, Javier: Los límites de la libertad de expresión..., op. cit., p. 236.

32 Magdaleno Alegría, Antonio: «Libertad de expresión, terrorismo y límites de los derechos fundamentales», Revista de Derecho Politico, $N^{o}$. 69, UNED, 2007, p. 187. 
particularidades y casuística existente. Por otro lado, sentencias como la STC 219/1992, de 3 de diciembre, defienden la veracidad como un requisito de constitucionalidad que impera en la información y que debe asumirse para redundar en la formación de una opinión pública libre y plural, propia de un Estado democrático ${ }^{33}$. Esta sentencia señala que la prevalencia de la libertad de información frente a otros derechos requiere que la información transmitida sea veraz y que se diferencie si es información o juicio de valor. Un elemento que consideramos determinante para contribuir a una adecuada formación de la opinión pública.

\section{La formulación de la información veraz en el periodismo. Elementos y características}

El concepto de veracidad se compone de varios elementos según reconoce la doctrina constitucional. La información debe versar sobre hechos objetivos y reales, que no pueden ser manipulados ni desvirtuados. Además, esa realidad fáctica debe ser comprobada razonablemente, no puede estar basada en rumores, invenciones o insinuaciones insidiosas. A todo ello debemos añadir que no hace falta que el hecho sea exacto o incontrovertible, pero si existe esa actitud diligente del profesional en la averiguación de la realidad de los hechos, es decir una actitud positiva hacia la verdad, con objeto de dar una información lo más correcta posible ${ }^{34}$. La noticia, basada en la objetividad y la neutralidad, debe ser contrastada con otros datos y fuentes, que permitan corroborar su veracidad, comprobando que no existe una base documental formada por rumores o insidias, que desvirtúen la realidad fáctica.

El periodista no sólo tiene la obligación de establecer la verdad sobre los hechos que investiga, sino que tiene también el deber de contar lo que sabe como cierto y lo que resulte noticiable. Esto se puede traducir bajo la premisa de que el periodista tiene la obligación de no callarse lo que sabe, siempre que sea de interés público. El destinatario de la información es el ciudadano, y la protección constitucional que se le otorga al periodista le permite acceder a la información que la fuente posee sobre los asuntos que maneja. Todo ello nos lleva a hablar de la ley, del ejercicio del poder cuya principal tendencia es permanecer, lo que genera una proclividad instintiva de los poderes hacia el oscurantismo, ya que la transparencia supone por sí misma un límite al

${ }^{33}$ STC 219/1992, de 3 de diciembre, FJ 2º . Asimismo y respecto a la formación de una opinión pública libre y plural propia de un Estado democrático debemos citar entre otras las SSTC 107/1988, 171/1990, 214/1991, 40/1992 y 85/1992.

${ }^{34}$ DE Carreras Serra, Lluis: Régimen jurídico de la información. Periodistas y medios..., op. cit., p. 48. 
ejercicio del poder ${ }^{35}$. Por tanto, es competencia del profesional de la información encontrar ese punto de equilibrio entre la verificación necesaria que una noticia requiere, y su fugacidad en la transmisión, actuando en defensa de ese interés público de una forma diligente. Las estructuras de poder tienden a conservar su control evitando filtraciones sobre su ejercicio, sin embargo, el amparo constitucional permite al periodista investigar y buscar información en el ejercicio de su profesión. La veracidad y la protección que le otorga la Constitución le va a servir para desarrollar adecuadamente su función, de ahí que fuera determinante, con la llegada de la democracia, la creación de una serie de instrumentos jurídicos que amparase la labor del profesional de la información. Unos medios de comunicación plurales, que permitan un ejercicio del derecho a la información, dentro de las bases constitucionales creadas para ello, permitiendo la formación de una opinión pública libre y el fomento de una sociedad democrática.

En relación con el contenido de la información debemos explicar que la noticia es el producto terminativo, el resultado del proceso comunicativoinformativo, que se abre con la captación de un hecho o acontecimiento y se cierra con la elaboración de un mensaje para conocer lo que pasa. El lenguaje empleado en la redacción de esa noticia exige referirse a unos hechos, datos y redactar un relato tendente a reflejar la realidad, en tal sentido el acto informativo es una forma de acto de justicia, con las implicaciones que ello tiene. Por tanto, la información se convierte en un acto de justicia que consiste no solo en dar información sino en analizar como la ofrecemos, redundando en la calidad informativa ${ }^{36}$. La veracidad se convierte aquí en un elemento intrínseco en el propio acto informativo, desde el mismo momento que la recogida de datos exige una relación de los hechos que describimos con la realidad. Todo ello conlleva una interpretación del sentido clásico del término de justicia, así, desde el momento que el periodista transmite la realidad tal y como es, se produce un acto de justicia con el receptor de esa información.

La jurisprudencia ha instaurado una obligación general de la veracidad en la tarea periodística, que define su actuación. Esto implicaría que en cualquier caso, en el que una información resultara ser falsa, podría ser motivo para fundamentar una demanda contra su autor. Es decir, no habría que alegar un daño sufrido, sino que el mero hecho de que sea inveraz podría ser considerado como daño público ${ }^{37}$, que motiva la actuación

${ }^{35}$ Gavela Avella, Daniel: «Derecho a la información y medios de comunicación» en Boletín de la ANABAD, Tomo 49, n. 3 - 4, 1999, pp. 77-78.

${ }^{36}$ Fernández Areal, Manuel: «La protección de la verdad en la libre comunicación de los mensajes informativos», en Poder Judicial, $N^{o}$. Especial XIII, 1990, pp. 202.

37 Urias, Joaquín: Lecciones de derecho a la información, Editorial Tecnos, $2^{\text {a }}$ edicion, Madrid, 2009, p. 127. 
judicial. En esos términos lo recoge la STC 336/1993, de 15 de noviembre, cuando la libertad de expresión colisiona con otros derechos como el honor $^{38}$. Con esta medida se está determinando un modo de actuar para el profesional de la información, en el que la búsqueda de la veracidad lo protege frente a lo publicado.

La STC 176/1995, de 11 de diciembre reconoce que la afirmación de la verdad absoluta, conceptualmente distinta de la veracidad como exigencia de la información, es la tentación permanente de quienes ansían la censura previa. Nuestro juicio ha de ser en todo momento ajeno al acierto o desacierto en el planteamiento de los temas o a la mayor o menor exactitud de las soluciones propugnadas, desprovistas de cualquier posibilidad de certeza absoluta o de asentimiento unánime por su propia naturaleza, sin formular en ningún caso un juicio de valor sobre cuestiones intrínsecamente discutibles, ni compartir o discrepar de opiniones en un contexto polémico ${ }^{39}$. El Tribunal Constitucional viene a reconocer la exigencia de la veracidad en las informaciones, con una definición muy diferente a los conceptos de verdad absoluta en las que pueden caer determinados sectores, que ejercen la censura. Las opiniones pueden ser variables, diferentes y no deben ser un asentimiento absoluto, sino que pueden ser cuestionables y discutibles.

El aumento cuantitativo de información y el incremento de la rapidez de los procesos de comunicación exige que los datos que reciben los ciudadanos estén dotados de significado ${ }^{40}$. En el mundo informativo, tal y como nos explica la STC 297/2000, de 11 de diciembre o la STC 99/2011, de 20 de junio, la presentación de una noticia constituye por lo general el resultado de una reconstrucción o interpretación de hechos reales en la que intervienen distintos factores, que pueden conducir a versiones dispares sobre una misma realidad, que además servirá para su contraste con aquellas otras versiones vertidas en el mismo espacio público informativo a efectos de la pertinente formación de la opinión pública ${ }^{41}$. En esas versiones evidentemente debe imperar el principio de la veracidad, para que puedan ser admitidas y gozar de garantías jurídicas.

${ }^{38}$ STC 336/1993, de 15 de noviembre, FJ $7^{\circ}$ : «...la prevalencia del derecho a comunicar libremente información sobre el derecho al honor sólo opera cuando existe relevancia pública de lo comunicado y, además, se trata de información veraz. En particular, por lo que respecta al segundo de estos requisitos, se ha declarado que a los profesionales de la información incumbe el «deber de comprobación razonable de la veracidad de la información», pues al asumir y transmitir a la opinión pública la noticia «también asume personalmente su veracidad o inveracidad» (SSTC 172/1990, 40/1992 y 219/1992, entre otras)»».

39 STC 176/1995, de 11 de diciembre, FJ $2^{\circ}$.

40 Azurmendi Adarraga, Ana: «De la verdad informativa a la «información veraz» de la Constitución...», op. cit., p. 13.

${ }^{41}$ STC 297/2000, de 11 de diciembre, FJ 10² STC 99/2011, de 20 de junio, en su FJ $5^{\circ}$. 
A ello debemos añadir que, aunque la veracidad es un requisito para disfrutar de la protección constitucional, no podemos determinarla como una condición de legitimidad de cualquier información pues atentaría contra el principio de libertad del artículo 20 de la CE. Por un lado, se defiende que la Constitución ampara las informaciones veraces, pero eso tampoco implicaría que todas las inveraces queden automáticamente prohibidas. Esto nos abocaría a reprimir la falta de veracidad cuando afectase a otros bienes y derechos de terceros ${ }^{42}$. Por ello, es de gran importancia que el Tribunal Constitucional marque claramente esos criterios en los que debemos apreciar la falta de veracidad de una información, pues ahí residen los motivos de una condena o no a un profesional, cuya noticia genere perjuicios o colisión de derechos.

En ocasiones se observa que la jurisprudencia se refiere solo a la veracidad en general sin descender a otros detalles, concediendo a los términos usados el sentido que tienen en el contexto en el que se encuentran. En otras circunstancias cuando la información difundida se refiere a las declaraciones de un tercero, su veracidad debe ser contrastada, es decir la verdad o falsedad de la información se consideraría sólo con respecto a la difusión de las declaraciones, pero no con respecto al contenido de las declaraciones mismas. Y en aquellos casos en los que la cuestión de la veracidad se dilucida en una sede jurisdiccional, cobra especial importancia la dimensión procesal de su prueba $^{43}$. Incluso el propio Tribunal Constitucional ha reconocido ese diferente tratamiento de la veracidad en función de la colisión de derecho que se ha producido. Elementos de conflictos, que son objeto de una casuística muy variada, llena de matices donde el factor probatorio adquiere una importante definición.

Solozábal mantiene que la vigencia de los derechos fundamentales en las relaciones entre particulares, supone que de un ejercicio lícito de los mismos no puede, de conformidad con la doctrina del TC, derivarse sanción alguna. El derecho fundamental de transmisión de información, es decir comunicación de hechos o conductas, ámbito a que se refiere el artículo 20 de la CE, es una garantía constitucional que no cubre a toda la información, sino exclusivamente a la veraz, entendiendo por veracidad no solo la calidad de la información que se corresponde con la realidad, sino también aquella vertida por el comunicante. En este sentido hay que matizar que incluso aunque la información puede ser inexacta, siempre debe ser obtenida de acuerdo con un

${ }^{42}$ URIAS, Joaquín: Lecciones de derecho..., op. cit., p. 127- 128.

${ }^{43}$ Rodríguez, Ángel: «Libertades Públicas I: La libertad de circulación y residencia, la libertad de expresión y el derecho de reunión y manifestación»e en VV. AA: Manual de Derecho Constitucional, Editorial Tecnos, 6 edición, Madrid, 2015, p. 510. 
canon razonable de cuidado profesional ${ }^{44}$, que quede amparada en la protección de la norma constitucional.

Para que el ejercicio del derecho a la información sea conforme con la Constitución tienen que concurrir varios elementos. Así, es necesario la veracidad de la información, con un carácter de interés general, que además pueda servir a la formación de una opinión pública libre. También demanda que el mensaje se transmita por profesionales de la información a través de un medio de comunicación institucionalizado. En consecuencia, todo ello va a contribuir a la formación de la opinión pública, convertida en un eje en torno al cual gira el derecho a la información ${ }^{45}$. La actuación de diligencia del profesional se verificará teniendo en cuenta varios elementos destacados jurisprudencialmente como el carácter del hecho noticioso, la fuente que proporciona la información, así como la comprobación de datos, contrastando las fuentes de la noticia ${ }^{46}$. Lo que se pretende con ello, es crear un marco de desarrollo del derecho a la información, acudiendo a criterios como la veracidad, la formación de la opinión pública o la profesionalidad en su ejercicio, a través de una actuación diligente. Partiendo de estos posicionamientos, podemos entender el amparo y la tutela que ofrece la norma constitucional en el ejercicio del derecho a la información.

\section{EL VALOR JURÍDICO DE LA VERACIDAD, LA COLISIÓN DE DERECHOS Y EL EJERCICIO DEL DERECHO A LA INFORMACIÓN.}

\section{La veracidad como límite del derecho a la información.}

El requisito de la veracidad puede ser analizado según se trate del derecho al honor o el derecho a la intimidad. La veracidad puede funcionar como causa legitimadora de las intromisiones en el honor, mientras que, en el derecho a la intimidad, esa veracidad es presupuesto necesario para que la intromisión se produzca. Se puede por tanto afirmar que, la legitimidad de las intromisiones en la intimidad de las personas se debe a la relevancia pública del hecho divulgado, es decir su comunicación debe ser justificada en función del interés público del asunto del que se informa y no solo por el hecho de que los datos sean veraces, tal y como lo han reseñado sentencias como

${ }^{44}$ Solozábal Echevarria, Juan José: «Libertad de expresión, información y relaciones laborales», en Revista Española de Derecho Constitucional, No. 26, Mayo-Agosto 1989, p. 168.

45 Pérez Royo, Javier: «Derecho a la información» en Boletín de la ANABAD, Tomo 49, n'. 3-4, 1999, p. 26.

${ }^{46}$ Navas Castillo, Florentina: «Libertad de expresión y derecho...», op. cit., p. 104. 
STC 197/1991, de 17 de octubre ${ }^{47}$, donde observamos que la veracidad adquiere una definición determinante en función del derecho con el que colisiona.

Desde la perspectiva del ordenamiento constitucional español toda limitación de un derecho fundamental tiene que estar justificada en la propia Constitución ${ }^{48}$. Eso significa que cuando se producen colisiones entre el derecho a la información y el derecho al honor, intimidad y propia imagen, el TC acude a ciertos criterios para resolver las controversias que se pueden suscitar. Así, podemos matizar que el requisito de veracidad no justifica intromisiones en el derecho a la intimidad si una noticia carece de relevancia pública, en un claro intento de extender la protección de las estructuras más íntimas de nuestra esfera personal y familiar. Lo explica entre otras, la STC 115/2000, de 5 de mayo, en la que la filtración de informaciones intimas y familiares a medios de comunicación por parte de personas que trabajan en la vivienda personal, aun siendo verdaderas no exime de responsabilidad jurídica ${ }^{49}$, lo que abre todo un posicionamiento doctrinal en este sentido.

La exigencia constitucional de la información veraz nos lleva a establecer una serie de diferencias entre el derecho a la información y la libertad de expresión, como hemos ido destacando en la investigación. Si bien es conveniente señalar que mientras que el derecho a la información versa sobre hechos, residiendo en el campo de lo objetivo, la libertad de expresión lo hace sobre opiniones, entrando en el campo subjetivo ${ }^{50}$. El derecho a la libertad de expresión versa por tanto sobre pensamientos, ideas y opiniones, en tanto que el derecho a la libertad de información se basa en la comunicación informativa de hechos veraces y noticiables, haciendo precisamente de esa

47 STC 197/1991, de 17 de octubre, FJ $2^{\circ}$.

48 Magdaleno Alegría, Antonio: «Libertad de expresión y partidos políticos en la jurisprudencia del Tribunal Europeo de Derechos Humanos», AFDUDC, $N^{o} 11,2007$, p. 449.

${ }^{49}$ La STC 115/2000, de 5 de mayo, explica en el FJ $7^{\circ}$, el requisito de veracidad en la colisión de derechos. El Tribunal Constitucional señala que: «...el requisito de la veracidad de la información merece distinto tratamiento «según se trate del derecho al honor o del derecho a la intimidad, ya que mientras la veracidad funciona en principio como causa legitimadora de las intromisiones en el honor, si se trata del derecho a la intimidad actúa en principio, en sentido diverso. El criterio para determinar la legitimidad o ilegitimidad de las intromisiones en la intimidad de las personas no es el de la veracidad, sino exclusivamente el de la relevancia pública del hecho divulgado, es decir, que su comunicación a la opinión pública, aun siendo verdadera resulte ser necesaria en función del interés público del asunto sobre el que informa», como hemos declarado en la STC 172/1990, de 12 de noviembre, FJ $2^{\circ} . »$

${ }^{50}$ Ortega Gutiérrez, David: El Derecho a la comunicación, Editorial Centro de Estudios Ramón Areces, Madrid, 2008, p. 126. 
distinción entre lo objetivo y lo subjetivo las fronteras para marcar límites y diferencias en un contenido informativo.

Una de las mejores aportaciones en el ejercicio de la libertad informativa es el que encontramos en el periodismo de investigación, interesado en una indagación plural, convenientemente profesionalizada en lo que atañe a sondeos y encuestas, rigurosa en el análisis de datos y centrada en la verdad. El destinatario de esa información puede sentirse atraído por un proceso periodístico, que despierta su curiosidad y que tiene una información contrastada y con pruebas ${ }^{51}$. El problema surge cuando se da como válido el rumor sin contrastar y además, el medio de comunicación difunde esa información carente de verificación. Podemos defender que la falta de rigor informativo supone falsear la realidad, vulnerando también el derecho del receptor del mensaje a recibir esa información veraz. Pese a todo lo dicho, no podemos obviar que la falta de veracidad puede, en ocasiones, suponer también una clara difamación, especialmente y desde un punto de vista práctico cuando se emiten informaciones de hechos falsos, que ofenden a la reputación de una persona $^{52}$. Ese daño que provoca la publicación de una información falsa, exige una respuesta jurídica o sanción, produciendo la excepción de veracidad y por tanto, perdiendo la protección que la norma constitucional ofrece. Llegados a este punto debemos avanzar en la investigación, analizando el concepto de diligencia profesional en el principio de veracidad.

\section{Diligencia profesional y responsabilidad del autor}

Tal y como desarrolla el Tribunal Constitucional en sentencias como la STC 61/2004, de 19 de abril o STC 53/2006, de 27 de febrero lo relevante para la veracidad informativa no es que a posteriori se pruebe en un proceso la realidad de los hechos, sino el grado de diligencia observado para la comprobación con anterioridad a la publicación de aquéllos ${ }^{53}$. En consecuencia, se establece la obligación de contraste como una forma de comprobar la veracidad de los hechos y un claro respeto a la difusión de una información ante la opinión pública.

Asimismo, debemos destacar que también las exigencias de la veracidad serán diferentes según el tipo de publicación. No es lo mismo hablar de cartas al director, declaraciones de tercero o reportajes neutrales, en los que no es el periodista quien informa y opina sino otras personas. En estos supuestos

${ }^{51}$ García Alcalde, Guillermo: «El valor social de la información un concepto a objetivar», en Poder Judicial, $N^{o}$. Especial XIII, 1990, p. 119.

${ }^{52}$ Gardini, Gianluca: Le regole dell informazione. Principi guridici, strumenti, casi, Paravia Bruno Mondadori, Milano, 2005, pp. 64-66.

${ }^{53}$ STC 61/2004, de 19 de abril FJ 5º STC 53/2006, de 27 de febrero, FJ $4^{\circ}$. 
bastaría con una diligente comprobación del autor de la carta o las declaraciones, y que lo publicado responde fielmente a lo declarado por él, independientemente de que refleje la realidad de los hechos ${ }^{54}$. Con esta medida, el profesional de la información traslada la responsabilidad de la declaración y su veracidad a la fuente que transmite unos hechos. Algo que la jurisprudencia constitucional destaca en la STC 336/1993, de 15 de noviembre, cuando señala que la autorización de la publicación de una carta posibilita el ejercicio de la libertad de expresión de su autor y su derecho a comunicar una opinión ajena al medio, aunque se insiste en la necesidad de salvaguardar el derecho constitucional de los lectores a recibir una información veraz ${ }^{55}$. No obstante, el Tribunal Constitucional determina una diligencia mínima exigible al medio de comunicación, que le impone por una parte la identificar al sujeto que emite las opiniones o noticias, así como la exigencia de cierto control del fundamento de la información proveniente de sujetos externos ${ }^{56}$. Por otro lado, como insiste la STC 22/1995, de 30 de enero, constatada la verdad del hecho de una declaración por ejemplo en un reportaje de una revista, el Tribunal insiste que no sería responsable el medio de la veracidad de lo declarado, pues tal responsabilidad sólo sería exigible al autor de la declaración $^{57}$. Esa distribución del grado de responsabilidad que involucra al autor emisor de la opinión y al medio, permite dilucidar muchos de los problemas que se plantean en la justicia ordinaria.

Todo ello, debe ser completado con las referencias que establece el Tribunal Constitucional al tratar la cuestión de la veracidad y la diligencia, en numerosos ejemplos como la STC 41/1994, de 15 de febrero o la STC 158/2003, de 15 de septiembre. En estas sentencias el Alto Tribunal insiste en la necesidad de una veracidad, que no equivale a una «realidad incontrovertible de los hechos». Es decir, implícitamente es una exigencia para el que la difunde, que consiste en un deber de buscar la verdad, y que evita que constitucionalmente se otorgue protección a insinuaciones o invenciones ${ }^{58}$. El Derecho Constitucional debe dar protección a aquel que lo merezca, y ensalzar las virtudes implícitas del derecho a la información, en un ejercicio profesional frente a la difusión de infundios que carecen de veracidad.

Para disfrutar de la tutela constitucional, la libertad de información debe cumplir con la exigencia de veracidad, siempre que entendamos esa correspondencia entre hechos transmitidos y realidad. La jurisprudencia del Tribunal Constitucional, refiriéndose a esa información periodística, considera en

\footnotetext{
${ }^{54}$ Torres del Moral, Antonio: Principios de derecho constitucional..., op. cit., p. 446.

55 STC 336/1993, de 15 de noviembre, FJ $7^{\circ}$.

56 STC 41/1994, de 15 de febrero, FJ 5º STC 158/2003 de 15 de septiembre, FJ $4^{\circ}$.

57 STC 22/1995, de 30 de enero, FJ $3^{\circ}$.

58 STC 41/1994, de 15 de febrero, FJ $3^{\circ}$.
} 
un primer momento que la pluralidad de fuentes informativas era garantía de veracidad de la información. Más adelante consideró la veracidad como una exigencia intrínseca para obtener la tutela constitucional, equiparándose esa veracidad con una razonable diligencia profesional en la obtención de la información, admitiendo que las noticias erróneas son inevitables en un debate libre ${ }^{59}$. Hay que señalar que para resolver muchos de los conflictos señalados el Tribunal Constitucional desde mediados de noventa introdujo la doctrina del reportaje neutral en la STC 41/1994, de 15 de febrero ${ }^{60}$, que posteriormente generó un desarrollo en sentencias como STC 144/1998, de 30 de junio, STC 134/1999, de 15 de julio, STC 76/2002 de 8 de abril, STC 54/2004, de 15 de abril, STC 1/2005 de 17 de enero o STC 53/2006, de 27 de febrero, entre otras. Esta jurisprudencia destaca que se ejerce la libertad de información cuando el contenido transmitido sea literal y fiel reproducción de lo escrito o dicho por un tercero, considerando por tanto que la información es veraz ${ }^{61}$. Este criterio permite recoger el criterio de veracidad con total exactitud recayendo en el autor original o tercero la responsabilidad de lo escrito. Un planteamiento científico de gran interés, merecedor de un tratamiento más detallado y particular en otra investigación.

Dentro de los problemas suscitados con la libertad de expresión y el derecho a la información, entendemos de gran interés y nos aporta una perspectiva novedosa en el análisis del artículo 20 de la CE y en el estudio de la veracidad informativa, la STC 86/2017, de 4 de julio. Esta sentencia viene motivada por el recurso de inconstitucionalidad interpuesto en relación con diversos preceptos de la Ley 22/2005, de 29 de diciembre, de la comunicación audiovisual de Cataluña. Así, la sentencia señala que el art. 80 f) de la Ley 22/2005 plasma la exigencia constitucional de que la información sea veraz, entendiéndola como el resultado de una investigación diligente ${ }^{62}$. Si bien el acierto de esta sentencia reside en el profundo estudio de la actitud de diligencia, que exige que el profesional con carácter previo a la difusión de la noticia indague los hechos y los verifique. No se trata por tanto de buscar una verdad absoluta sino más bien de una forma de proceder tal y como señala la referida sentencia.

Sin embargo, esa actitud procedimental debe partir de forma individual pues carecemos de fórmulas de regulación del ejercicio profesional periodístico. A diferencias de otros países democráticos, el periodismo en países como España carece de mecanismos de autorregulación de la profesión, que

${ }^{59}$ García Guerrero, José Luis: «Una visión de la libertad de comunicación...», op. cit., p. 374.

60 STC 41/1994, de 15 de febrero, FJ $5^{\circ}$.

${ }^{61}$ Fernández Montalvo, Rafael: «Las libertades de información...», op. cit., p. 127.

${ }^{62}$ STC 86/2017, de 4 de julio, FJ $5^{\circ}$. 
vigile los abusos que le perjudican. La verdad como materia prima de la información está devaluada. El trabajo de los periodistas sufre un descrédito importante, un fenómeno que muestra hasta qué punto está divorciada la profesión periodística de una parte importante de la sociedad ${ }^{63}$. No obstante, las instituciones reconocen en la información veraz la necesidad para verificar el cumplimiento de derechos ${ }^{64}$. Actualmente el periodismo ha perdido la fuerza intrínseca que en otros tiempos tuvo, y que lo convirtió en el Cuarto Poder. La figura del periodista se ha visto afectada por un descrédito social, y una mezcla de intereses que han perjudicado su imagen, creando un periodismo artificioso y maniqueísta.

\section{La protección constitucional en el ejercicio del derecho a la información}

Desde la lógica jurídica, un derecho genérico a la veracidad llevaría inaceptables restricciones de la libertad de información. No debemos olvidar que el derecho a la información veraz, exige un contraste de datos que en muchos casos se cumple con la publicación de distintas versiones contrapuestas y no con la exigencia de veracidad de cada una de las informaciones. Lo que el Tribunal Constitucional consolida es el derecho de los ciudadanos a recibir una información veraz, sin existir cauces para exigir su cumplimiento ${ }^{65}$, quedando más como una aspiración a realizar más que un verdadero objetivo logrado.

Sentencias como la STC 139/2007, de 4 de junio inciden en la necesidad de que el medio informativo sea un mero transmisor de las narraciones o que el objeto de la noticia incluya declaraciones puestas en boca de personas determinadas responsables de sus expresiones, dentro de un contexto informativo $^{66}$. Es indiscutible que siempre tenemos que analizar una actitud responsable para gozar de la protección constitucional, pero tampoco el uso de un importante número de fuentes puede ser considerado como garantía de veracidad. Un mal enfoque informativo puede derivarnos a múltiples fuentes que, evidentemente, tampoco nos dan certeza absoluta, aunque siempre será una garantía para el periodista cuando justifique la diligencia debida en la búsqueda de información. Esta línea de la diligencia y responsabilidad del

${ }^{63}$ De la Cuadra Fernández, Bonifacio: «El ejercicio de la libertad de expresión en los medios de comunicación social y sus límites», en Poder Judicial, $N^{o}$. Especial XIII, 1990, p. 246

${ }^{64}$ Luna Pla, Issa: «Empoderamiento pro-desarrollo humano con información pública» en VV. AA: Derecho Comparado de la Información, Universidad Nacional Autónoma de México, Instituto de Investigaciones Científicas, México, 2013, p. 88.

${ }^{65}$ Urias, Joaquín: Lecciones de derecho..., op. cit., p. 128.

${ }^{66}$ STC 139/2007, de 4 de junio, FJ 11º. 
profesional de la comunicación en el tratamiento informativo, puede ser más acorde con la actitud que debemos exigir, pero también no debemos obviar que pueden surgir informaciones poco exactas o contrastadas cuando hablamos de un flujo informativo tan complejo como el que vivimos en la actualidad. El gran problema en el que nos encontramos en los tiempos contemporáneos son las líneas informativas tan variadas; esa inmediatez de la información, a través de publicaciones digitales o formatos similares, que ha contribuido a un periodismo caracterizado en algún momento por la falta de rigurosidad y de fuentes contrastadas en el tratamiento informativo.

El profesional de la comunicación debe ser consciente de su derecho como ciudadano y de la obligación inherente como profesional que debe servir la verdad al público. Aun así, el periodista comprende que su trabajo tiene limitaciones y por ello, los libros de estilo de los medios de comunicación inciden en la necesidad de presentar la información con objetividad, impersonalidad y amenidad, siempre bajo el respeto a la intimidad individual y material, que marcará el límite de la permisible intromisión informativa $^{67}$. No hay que obviar que la libertad de información es necesaria en una sociedad democrática y que la jurisprudencia internacional la ha considerado como una «necesidad social imperiosa», en la que es determinante un equilibrio entre el derecho a la información y la tutela de la imagen y reputación de la persona, siendo una cuestión delicada determinar los límites por parte de los tribunales ${ }^{68}$, lo que inevitablemente nos lleva a utilizar el criterio de veracidad.

Como hemos explicado en el desarrollo de esta investigación, el Tribunal Constitucional ha subrayado la dificultad de separar la expresión de opiniones de la simple narración de hechos, pues la expresión de ideas y opiniones se apoya constantemente en la narración de los hechos y, a la inversa, en la narración se aprecia casi siempre algún elemento valorativo tendente a la formación de una opinión ${ }^{69}$, una situación que le exige analizar cada caso concreto atendiendo a las especiales particularidades. Sin embargo, al definir el concepto de «información veraz»o «diligencia profesional» el Tribunal lo ha determinado con criterios profesionales periodísticos, lo que nos

${ }^{67}$ Fernández Areal, Manuel: «El derecho a la información como garantía de libertad» en VV. AA: Información, libertad y derechos humanos: la enseñanza de la ética y el derecho a la información, Fundación COSO de la Comunidad Valenciana para el Desarrollo de la Comunicación y la Sociedad, Valencia, 2002, p. 133.

${ }^{68}$ Cardone, Andrea: «L'incidenza della libertà d'espressione garantita dall'art. 10 CEDU nell'ordinamento costituzionale italiano» en VV. AA: L'informazione il percorso di una libertà, Volume II, Passigli Editori, Firenze, 2012, p. 203.

69 STC 6/1988, de 21 de enero, FJ 5º; STC 174/2006, FJ $3^{\circ}$; STC 29/2009, FJ $2^{\circ}$; STC 50/2010, FJ $4^{\circ}$, y STC 79/2014, FJ $4^{\circ}$. 
hace entender que, quien ejerza el derecho a la información, aunque no sea profesional, se le exigirá un cumplimiento diligente y veraz como a un periodista.

La comprobación de la correspondencia de los hechos noticiables con la realidad, reposa sobre el mismo fundamento de la libertad de información. Sin embargo, también debemos referirnos a la posible protección constitucional de la información falsa pero diligente, que lesiona otros bienes jurídicos y que respondería al «principio de riesgo permitido justificado», aseverada en la función que desarrolla la opinión pública en nuestros modelos sociales. Por tanto, entenderíamos como veraz la imputación que se corresponda con la realidad, aunque esa realidad pueda ser errónea, siempre que se haya realizado el cumplimiento de los deberes de comprobación ${ }^{70}$. El principio de riesgo permitido justificado, se convierte en un eximente de responsabilidad para el periodista que asume el riesgo de que la información sea falsa, a pesar de haber realizado todo lo posible para verificar y contrastar la noticia. De todos modos, la protección constitucional lleva unos requisitos tasados por la jurisprudencia en los que podemos encontrar si realmente un profesional de la información ha verificado sus hechos noticiables, a través de ese contraste de fuentes. Es por ello que la jurisprudencia en los últimos años, ha establecido todo un canal de presupuestos de comprobación de los hechos objeto de noticia, en donde el elemento fáctico de la redacción de la noticia debe responder a un componente real de verificación.

A pesar de la imperfección de los sistemas democráticos y de los textos constitucionales, que exigen ciertas reformas ${ }^{71}$, hemos de destacar las virtudes que han traído a nuestras sociedades contemporáneas, desarrollando derechos tan básicos como la libertad de expresión y el derecho a la información. Tal y como señala Carrillo, la veracidad es un valor jurídico que opera como límite constitucional de la información ${ }^{72}$, algo de gran importancia en el consenso democrático. La comprensión que hace el Tribunal Constitucional del elemento de veracidad no como un reflejo de la verdad sino más bien siendo un reflejo de la necesaria vigilancia en la búsqueda de lo cierto o de la especial diligencia cuando se contrastan las informaciones ${ }^{73}$ ha sido determinante.

\footnotetext{
70 Álvarez García, Francisco Javier: El derecho al honor y las libertades de información y expresión, Tirant Lo Blanch, Valencia, 1998, pp. 96-97.

${ }_{71}$ Vera Santos, José Manuel: «La reforma del procedimiento de reforma constitucional», Revista de Derecho Político $n^{\circ}$. 96, mayo-agosto 2016, p. 17.

72 Carrillo, Marc: «Derecho a la información y veracidad informativa», Revista Española de Derecho Constitucional $n^{\circ}$. 23, Centro de Estudios Políticos y Constitucionales, 1988 , p. 191.

73 STC 51/1997, de 11 de marzo, FJ 5; STC 129/2009, de 1 de junio, FJ $2^{\circ}$ y STC 29/2009, de 26 de enero, FJ $4^{\circ}$.
} 
También es importante reseñar la insistencia que la jurisprudencia muestra en la exigencia de una rigurosa y total exactitud en el contenido de la información, negando la protección constitucional a aquellos que transmiten como verdaderos, hechos sin comprobar su veracidad ${ }^{74}$. El Alto Tribunal marca los criterios de protección que deben amparar al informador, desde el momento que hace una fiel vigilancia de la noticia, acercándose a la veracidad de los hechos, o al menos al más alto factor de verdad dentro de las fuentes que contrasta.

El Tribunal Constitucional ha procurado en sus veredictos proporcionar una categoría fundamental a la libertad de expresión y de información en su colisión con otros derechos, al considerarlo como un derecho básico para el reconocimiento y garantía institucional como es la opinión pública libre. Además, conforme ha ido avanzando y desarrollándose los valores democráticos, el Tribunal Constitucional ha definido con mayor profundidad sus fundamentos jurídicos siendo más riguroso en el análisis de estas cuestiones ${ }^{75}$, especialmente cuando la información veraz y los juicios de valor se combinan en un mismo texto periodístico.

En estas reflexiones finales debemos insistir que la veracidad es el presupuesto para considerar que nos encontramos ante una información constitucional protegida, pero en la ponderación de las circunstancias concurrentes, es decir cuando esa libertad de información entra en conflicto con otros derechos o bienes constitucionales, será el Tribunal Constitucional quien tendrá en cuenta ese interés público de la información. De hecho, no debemos obviar que en líneas generales hemos condicionado la protección constitucional de la libertad de información a que ésta se refiera a hechos con relevancia pública, en el sentido de noticiables, y a que dicha información sea veraz $^{76}$. Con ello, destacamos la función que el Tribunal Constitucional está determinando para definir el concepto de veracidad, así como los elementos subyacentes que caracterizan una información. Una labor de interpretación que, en los momentos actuales, cada vez es más necesario para consolidar un modelo constitucional y democrático, fomentando con ello un ejercicio activo del periodismo con plenas garantías jurídicas.

${ }^{74}$ Véase STC 320/1994, de 28 de noviembre en cuyo FJ $3^{\circ}$ se establece que «el derecho a emitir información veraz» ha sido subrayada por este Tribunal en reiteradas sentencias como las SSTC 105/1983, 51/1985, 107/1988, 143/1991, 178/1993. Junto a estas referencias también en un sentido similar podemos citar STC 28/1996 de 26 de febrero; STC 190/1996, de 25 de noviembre y STC 51/1997, de 11 de marzo, entre otras»».

${ }^{75}$ Rodriguez Gómez, Eduardo F.: «El Tribunal Constitucional y el conflicto entre la libertad de información y los derechos al honor, la intimidad y la propia imagen: revisión jurisprudencial», Estudios sobre el Mensaje Periodístico, Vol. 20, Núm. 2, 2014, p. 1212.

${ }^{76}$ STC 68/2008, de 23 de junio, FJ $3^{\circ}$ y STC 139/2007, de 4 de junio, FJ $7^{\circ}$. 


\section{BIBLIOGRAFÍA}

Álvarez GARCíA, F.J. El derecho al honor y las libertades de información y expresión, Tirant Lo Blanch, Valencia, 1998

AzUrmendi AdARraga, A. «De la verdad informativa a la «información veraz» de la Constitución española de 1978. Una reflexión sobre la verdad exigible desde el derecho de la información», Comunicación y Sociedad, Vol. XVIII, Núm. 2, 2005, pp. 9-48.

— Derecho a la información: guía jurídica para profesionales de la comunicación, Ceunsa, Navarra 2001.

BrajnOVIC, L. El ámbito cientifico de la Información, Eunsa, Pamplona, 1979.

CARdone, A. «L'incidenza della libertà d'espressione garantita dall'art. 10 CEDU nell' ordinamento costituzionale italiano» en VV. AA: L'informazione il percorso di una libertà, Volume II, Passigli Editori, Firenze, 2012.

CARrILlO, M. «Derecho a la información y veracidad informativa», Revista Española de Derecho Constitucional $n^{\circ}$. 23, Centro de Estudios Políticos y Constitucionales, 1988, pp. 187-206.

CRemades, J. Los límites de la libertad de expresión en el ordenamiento jurídico español, Ley-Actualidad, Madrid, 1995.

De Carreras Serra, L. Régimen jurídico de la información. Periodistas y medios de comunicación, Ariel Derecho, Barcelona, 1996.

De la CuAdra Fernández, B. «El ejercicio de la libertad de expresión en los medios de comunicación social y sus límites», en Poder Judicial, $N^{o}$. Especial XIII, 1990, pp. 243-250.

Escobar de la Serna, L. Principios de derecho de la información, Editorial Dykinson, Madrid, 2000.

FERNÁNDEZ AREAL, M. «El derecho a la información como garantía de libertad» en VV. AA: Información, libertad y derechos humanos: la enseñanza de la ética y el derecho a la información, Fundación COSO de la Comunidad Valenciana para el Desarrollo de la Comunicación y la Sociedad, Valencia, 2002.

— «La protección de la verdad en la libre comunicación de los mensajes informativos»), en Poder Judicial, $N^{\circ}$. Especial XIII, 1990, pp. 201-222.

FERnÁndez Montalvo, R. «Las libertades de información y expresión en el ámbito administrativo» en VV. AA: La libertad de información y expresión. Actas de las VII Jornadas de la Asociación de Letrados del Tribunal Constitucional, Centro de Estudios Políticos y Constitucionales, Madrid, 2002.

GARCÍA Guerrero, J.L. «La libertad de comunicación» en GARCÍA GUERRERO, José Luís: Los derechos fundamentales. La vida, la igualdad y los derechos de libertad, Tirant Lo Blanch, Madrid, 2013, pp. 151-209.

— «Una visión de la libertad de comunicación desde la perspectiva de las diferencias entre libertad de expresión, en sentido estricto, y libertad de información», Teoría y realidad constitucional $n^{\circ}$. 20, UNED, 2007, pp. 359 - 399.

— «Publicidad y libertad de expresión en el ordenamiento constitucional español», Derecho Privado y Constitución, $n^{\circ}$. 10, 1996, pp. 117-146.

García AlCALDE, G. «El valor social de la información un concepto a objetivar», en Poder Judicial, $N^{o}$. Especial XIII, 1990, pp. 117-122. 
Gardini, G. Le regole dell informazione. Principi guridici, strumenti, casi, Paravia Bruno Mondadori, Milano, 2005.

Gavela Avella, D. «Derecho a la información y medios de comunicación» en Boletín de la ANABAD, Tomo 49, nº 3 - 4, 1999, pp. 77-82.

Gutierrez DAVID, Mª.:E Justicia y medios de comunicación. Claves para la buena praxis de los derechos informativos, Editorial Fragua, Madrid, 2007.

HABERMAS, J. Historia y crítica de la opinión pública. La transformación estructural de la vida pública, Gustavo Gili, Barcelona, 1981.

LuNA PLA, I. «Empoderamiento pro-desarrollo humano con información pública» en VV. AA: Derecho Comparado de la Información, Universidad Nacional Autónoma de México, Instituto de Investigaciones Científicas, México, 2013.

Magdaleno Alegría, A. «Libertad de expresión, terrorismo y límites de los derechos fundamentales», Revista de Derecho Político, $N^{\circ}$. 69, UNED, 2007, pp. 181-218.

— «Libertad de expresión y partidos políticos en la jurisprudencia del Tribunal Europeo de Derechos Humanos», AFDUDC, $N^{\circ} 11$, 2007, pp. 431-449.

MuÑoz MACHADO, S. Libertad de prensa y procesos por difamación, Editorial Ariel, Barcelona, 1988.

Navas Castillo, F. «Libertad de expresión y derecho a la información», en Torres del Moral, Antonio: Libertades informativas, Editorial Colex, Madrid, 2009.

Ortega Gutiérrez, D. El Derecho a la comunicación, Editorial Centro de Estudios Ramón Areces, Madrid, 2008.

PÉREz Royo, F. «Derecho a la información» en Boletín de la ANABAD, Tomo 49, n. 3-4, 1999, pp. 19-34.

Rodríguez, A. «Libertades Públicas I: La libertad de circulación y residencia, la libertad de expresión y el derecho de reunión y manifestación» en VV. AA: Manual de Derecho Constitucional, Editorial Tecnos, 6 ${ }^{\text {a }}$ edición, Madrid, 2015.

Rodriguez Gómez, E.F. «El Tribunal Constitucional y el conflicto entre la libertad de información y los derechos al honor, la intimidad y la propia imagen: revisión jurisprudencial», Estudios sobre el Mensaje Periodístico, Vol. 20, Núm. 2, 2014, pp. 1209-1224.

SOlOZÁBAl ECHEVARRIA, J.J. «Libertad de expresión, información y relaciones laborales», en Revista Española de Derecho Constitucional, $N^{\circ}$. 26, Mayo-Agosto 1989, pp. 165-179.

TORRES DEL MORAL, A. «Límites de la libertad de comunicación pública y censura», en Torres del Moral, Antonio: Libertades informativas, Editorial Colex, Madrid, 2009.

- Principios de derecho constitucional español, Servicio de Publicaciones de la Facultad de Derecho, Universidad Complutense, Madrid, 2010.

URIAS, J. Lecciones de derecho a la información, Editorial Tecnos, $2^{\mathrm{a}}$ edición, Madrid, 2009.

Vera SANTOS, J.M. «La reforma del procedimiento de reforma constitucional», $R e$ vista de Derecho Político $n^{\circ}$. 96, mayo-agosto 2016, pp. 13-48.

VIILLAVERDE MENÉNDEZ, I. «Introducción histórica a las libertades de información y expresión», en VV. AA: La libertad de información y de expresión. Actas de las VII Jornadas de la Asociación de Letrados del Tribunal Constitucional, Centro de Estudios y Constitucionales, Madrid 2002. 


\title{
EL DERECHO A RECIBIR INFORMACIÓN VERAZ EN EL SISTEMA CONSTITUCIONAL. \\ EL EJERCICIO PROFESIONAL DEL PERIODISMO COMO GARANTIIA DEMOCRÁTICA
}

The right to receive faithful information in the constitutional system. The professional exercise of journalism as a democratic guarantee

\author{
Jesús López de Lerma Galán \\ Universidad Rey Juan Carlos (España) \\ jesus.lopezdelerma@urjc.es
}

http://dx.doi.org/10.18543/ed-66(2)-2018pp435-459

\section{Copyright}

Estudios de Deusto es una revista de acceso abierto, lo que significa que es de libre acceso en su integridad. Se permite su lectura, la búsqueda, descarga, distribución y reutilización legal en cualquier tipo de soporte sólo para fines no comerciales, sin la previa autorización del editor o el autor, siempre que la obra original sea debidamente citada y cualquier cambio en el original esté claramente indicado 